\title{
A NOVEL APPROACH ON A ROBOT FOR THE BLIND PEOPLE WHICH CAN TRAINED AND OPERATED BY A NON EXPERT USER
}

\author{
T.Saranya ${ }^{1}$, S.Muralimohan ${ }^{2}$ \\ ${ }^{1} P G$ Student M.Tech (ES), ECE Department, SVCET, Chittoor, AP, India \\ ${ }^{2}$ Associate Professor, ECE Department, SVCET, Chittoor, AP, India
}

\begin{abstract}
The aim of this paper is, to design a robot for the blind people. Here we are implementing a robot model; by using it we can give a voice message to the blind people about the name of the objects which are present in his way. The main use of this model is a blind person can also walk as a normal person without others help. And also another feature here is, a non expert person also can able to teach to the robot about the newly learning of visual objects. Here we are using ARMI1 processor, so we can have many of the advanced features also. Here we are using a camera; it is capturing the things which are there in front of the robot. And it will send the image to the processor and then as per the commands by the user it may save the image or compare the image with the existing data base. If the command is recall means it will recall the object name if the object present in the data base and then it will give its corresponding name as a voice message to the blind people through the ear phone.
\end{abstract}

Keywords: Human robot interface, Speeded-up Robust Features (surf), openCV.

$* * *$

\section{INTRODUCTION}

If we see there are so many people are blind in this world by birth onwards and also some people are became blind because of any accidents or otherwise because of some other reasons also. And some people became blind because of their aging reasons also. But being a blind people living in this world is very difficult. So to help such people already there are many type of instruments and among them robots are having their own recognization. Here in this paper we are trying to implement a robot model. This robot will help to the blind person in such a way that, it is having a earphone, if the blind person walks along with this robot by wearing that earphone then this will continuously gives a voice message to that person. Then he will take care of that object. And also it is having some unique nature that is, teaching of new visual objects. That means here a non expert person can able to teach the new visual objects to the robot. In existing systems there are bags of words present as a data base which is given to the robot by the designer. That means he was supposed to train the robot all the things in this world at most. That's why it became as a collection of database. That requires much more memory and also there will be another problem that is adjusting to the house hold environment. To avoid these types of problems here in this robot we are making the non expert user to train the new visual objects whatever he required and whenever it is.

\section{EXISTING SYSTEM}

That is in existing systems all the objects are taught to the robot by the manufacturer only. So this robot can able to recognize those things only. If in the user house there are any other things than he taught this cannot recognize those. This will become a drawback to the robot and also if we want to use this robot after some years, at that time there will be so many advanced things in that particular house. All those things cannot understand by the robot. But in our robot there is a facility that a non expert user can also teach to the robot at any time. Only thing here is a non expert user should know how to teach new visual objects to the robot. Then they can train to the robot in feature also. One more thing to be considered is a robot adjusting for the industrial environment is somewhat easy than that of adjusting for the house hold environment. Because industrial environment is fixed type of environment and what we can expect almost where as house hold environment is somewhat unknown and unexpected and continuously changing environment. So, here our robot is going to be work in house hold environment as a personal robot. So if the environment what a designer will have in his mind is differs from existing environment then the robot is supposed to face so many difficulties. So to avoid them here we are implementing this type of robot which can cable to guide by a non expert user. And one more thing here is this existing system may be an efficient one but it is having collection of data base. That is its data base is very huge one. So it requires much more memory to save this amount of data base. To avoid that here we are going for the advanced version of robot which is explained below.

\section{PROPOSED SYSTEM}

In proposed system what we are trying to implement is, a robot that can able to trained by a non expert person. That means, one person who needs a personal robot will buy it. And at that time the designer will guide to him how to train this robot. Then he will take this robot to the home and he will train to the robot all the things what he is having in his house. Then, He will let this robot to work for the blind people who are staying in that house. And whenever the house environment is changing or people buying new things 
at that time these people will train those things to the robot. Then this robot will be updated. And also we can use this robot for searching an object in a house. That means for example one wants search his cell phone in his house and he don't know where it is, at that time if he use this robot then it will continuously scan the house and it will recall all objects what it is seeing and simultaneously it is giving voice message. Then whenever it is finding his cell phone it will give its correspondence name as a voice message. Likewise we can able to search the things whatever it is having in its database.

\section{BLOCK DIAGRAM}

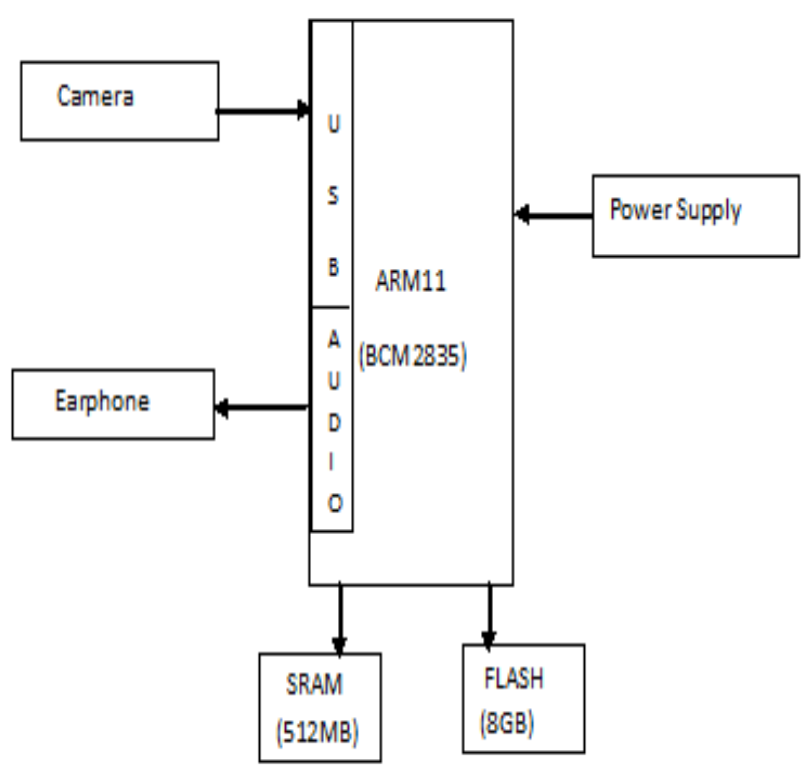

Fig 1: Block diagram of the proposed system

In this paper we are using an ARM11 controller. To the USB port of microcontroller we are connecting a camera and to the audio port earphone. Here cam is used to capture the object which is present in front of the robot. And the captured image will be going to save in the memory by using surf algorithm. And it requires $5 \mathrm{v}$ as a power supply. Here we are using SRAM(512MB) and FLASH(8GB) memories. Flash memory is extendable upto 32GB. But here we are using only 8GB. And the use of earphone is, whenever processor recalls the object it will give the corresponding name as voice message through this earphone only.

\section{FLOW CHART}

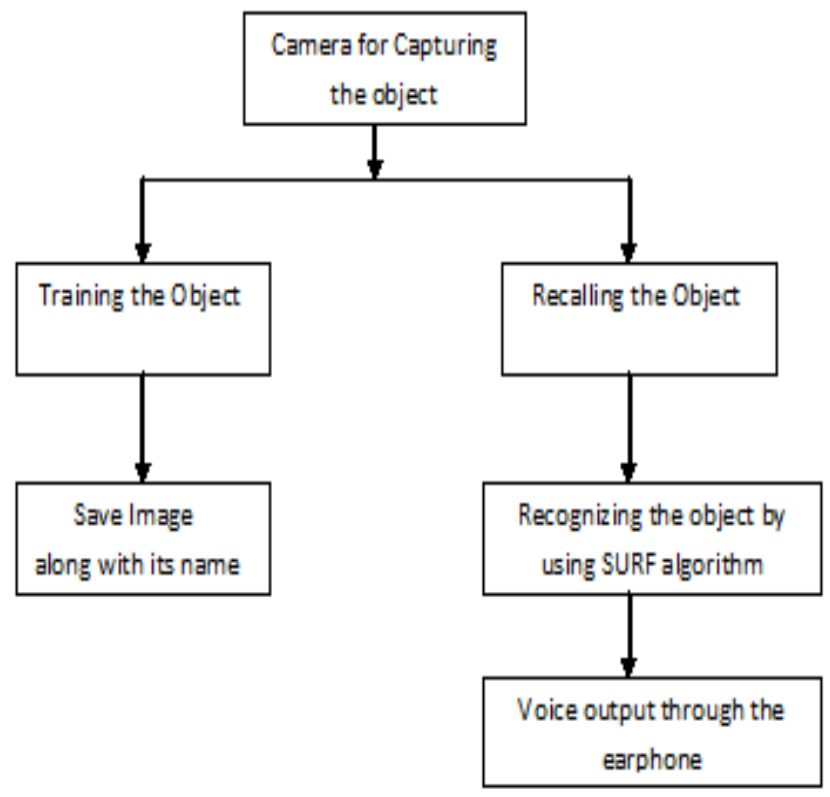

Fig 2 Flow chart of the execution processor of the proposed system

Coming to the execution process, first the camera will capture image and then here processor is waiting for the command from the user to decide whether it is to recall or to save the image. Here we are interfaced processor with a PC. So we can able to enter the commands through the key board. And this key board will act as a Human robot interface. First if we give "train" as a command then it will wait for the object name. Then, if we enter it will save the image along with its name. If we give "recall" as a command then the processor will check is there any image matching with the captured image. If any matches, the processor will recognize the image and collect the name of the image and gives corresponding name as a voice message by using the earphone. Here the processor is using openCV as a plat form and surf algorithm for the purpose of saving and comparing the object images. Here we require Embedded C and Surf algorithms as soft wares and ARM11 processor and camera are the required hard wares.

\section{EXPERIMENTAL SETUP}

Here we are going to place some objects in a particular room. And after that first we are going to train those objects to the robot and then after some time we will recall those objects in different order. In this way we are going to test the robot. But here sometimes if the room brightness differs between the two capturing times means for the same objects the results will be mismatched. For example we are going to take the following objects which are some of daily using things and let the robot to test. 


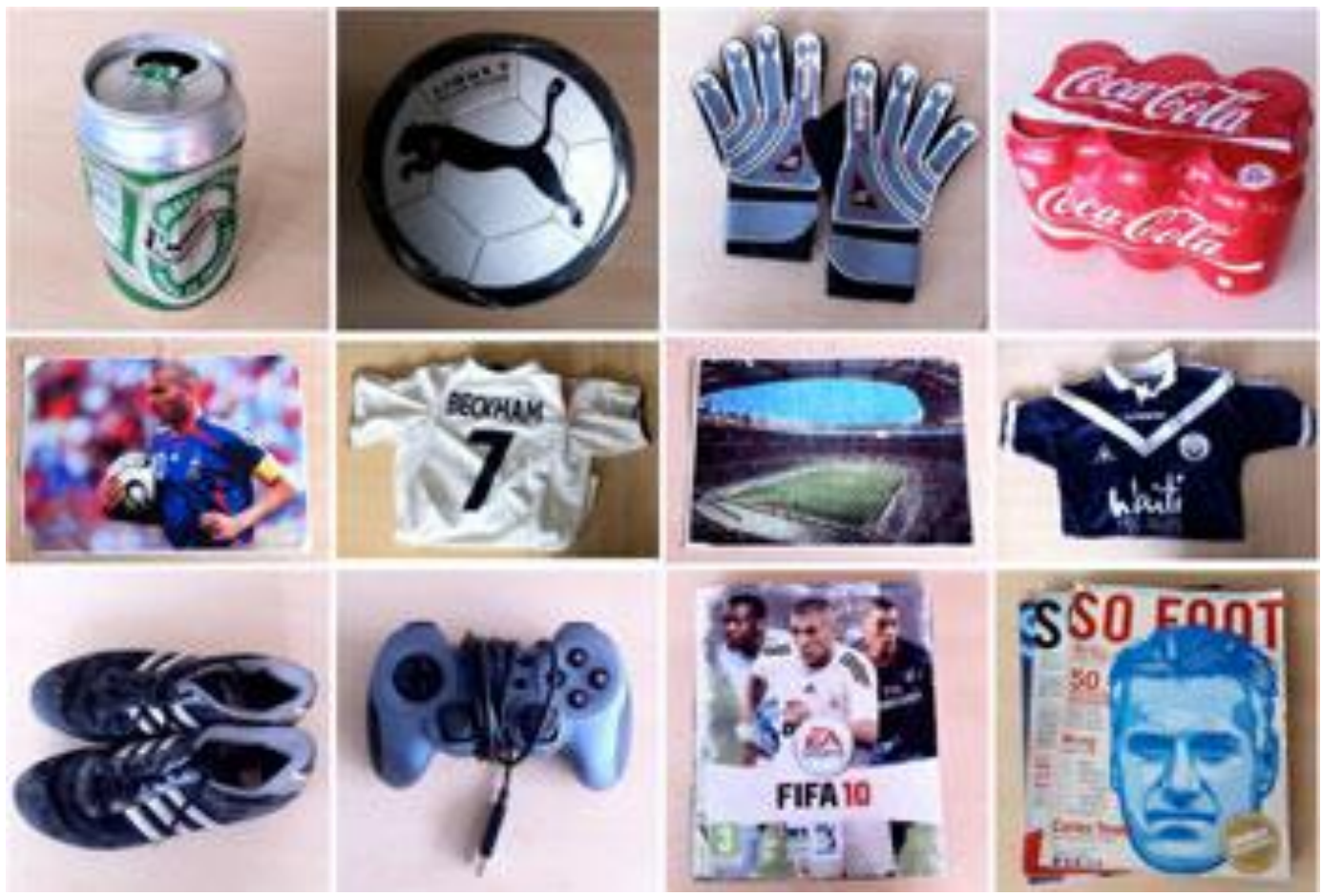

Fig 3 Some of the household things

\section{PHOTOSNAP OF THE KIT}

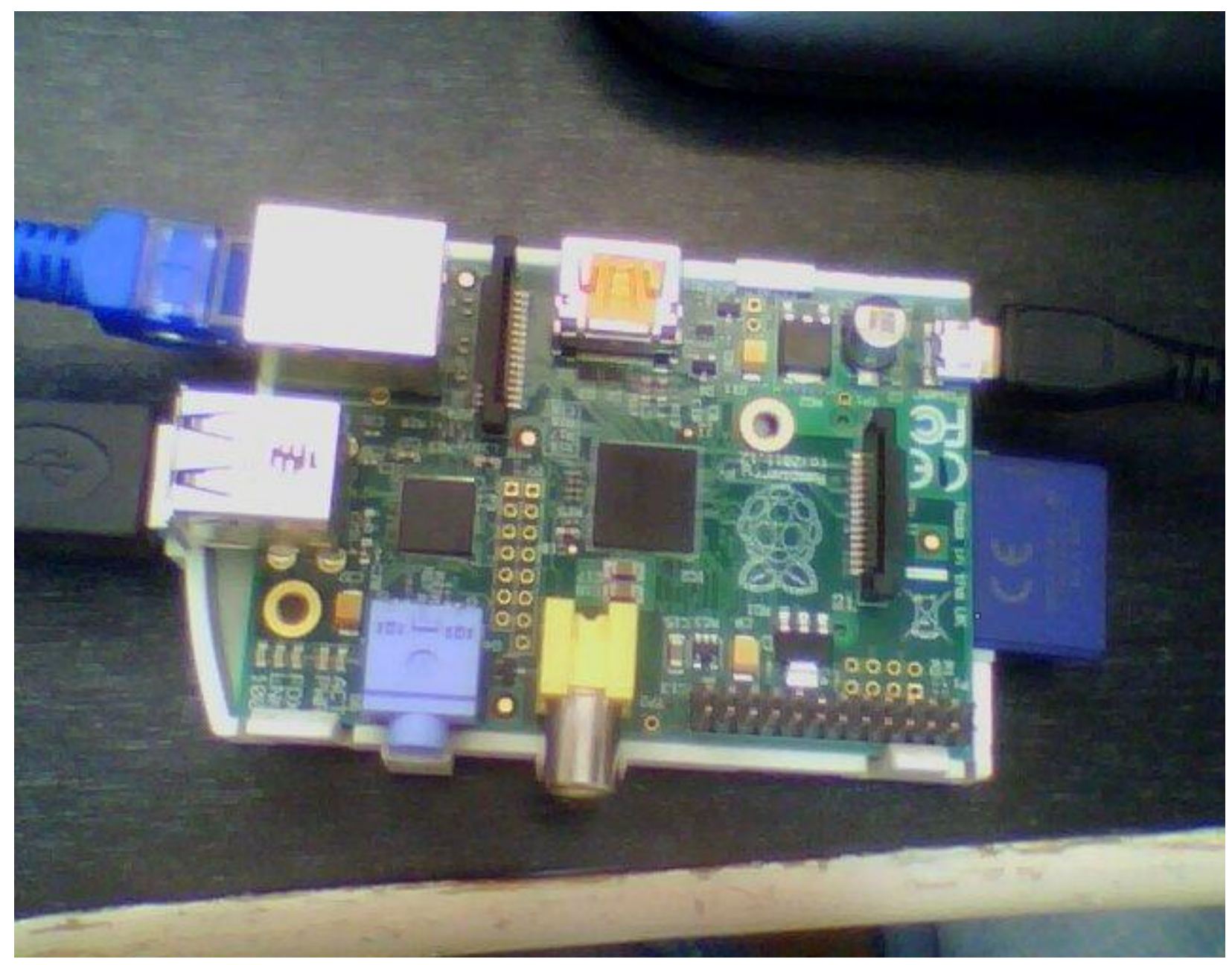




\section{RESULTS}

Here we are going to train and recall an object. Take box as an object and place it in front of the kit. Now camera will capture the picture of the box and it will send command as train or call as shown below.

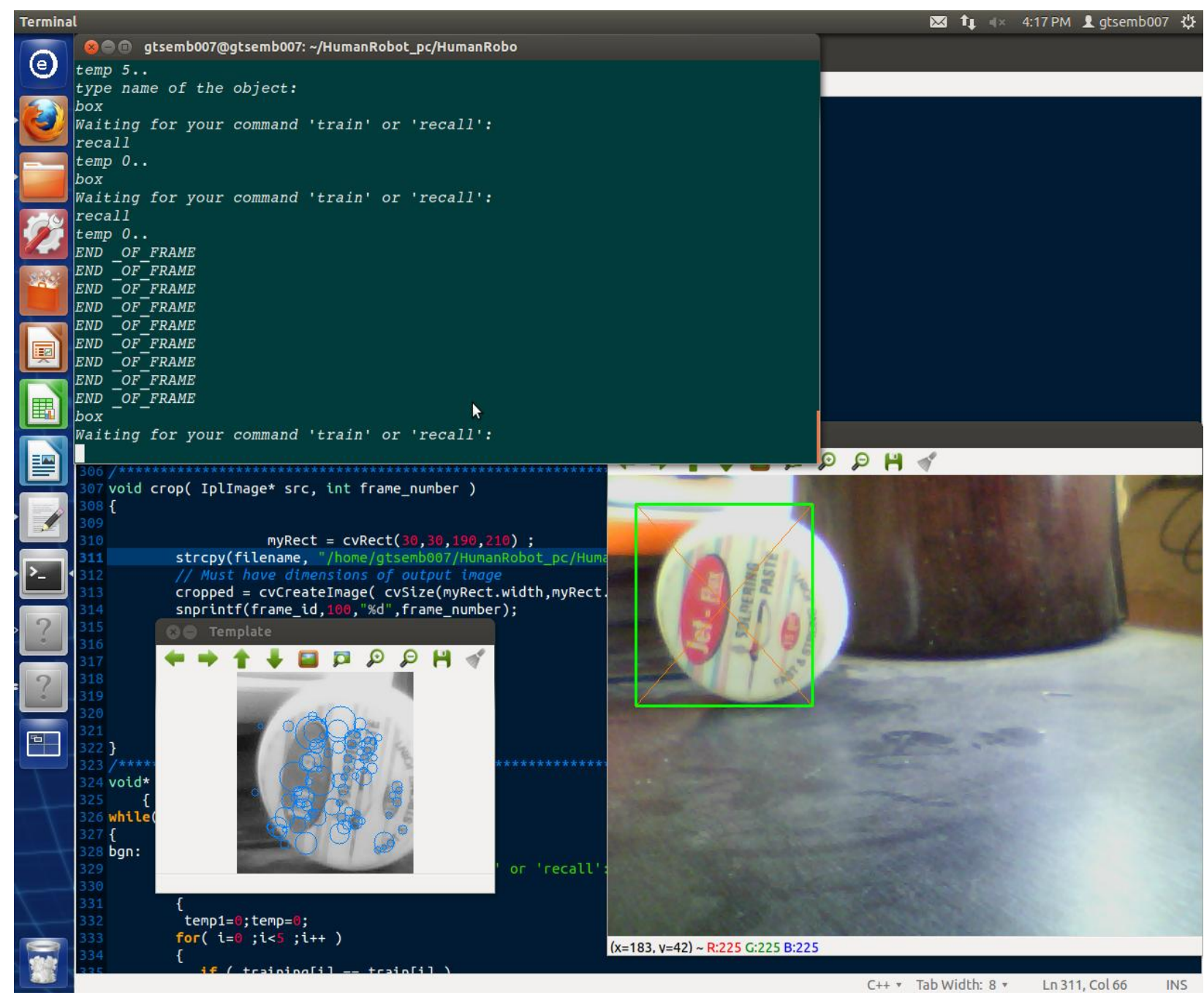

Now if you give train as command then it will ask enter the object name. Now enter box as object name. Then it will save object picture along with its name. In future if $u$ place box in front of the camera means it again wait for the command and if you enter recall as command then it will give box as a voice message through ear phone.

\section{ADVANTAGES AND DISADVANTAGES}

\section{Advantages}

- $\quad$ Required less memory

Here in this paper we are implementing a robot which can able to trained by a non expert person. Because of this feature the user will train the robot only required objects. So the required memory here will be much more less than that of the previously existing robots which are trained by the designer.

- $\quad$ Can easily update in feature

That is, in feature if advanced version of objects bought by the user those objects cannot able to identify by the previously existing robots but here those objects can able to trained by the user at that time also.

- It is very fast responding one.

\section{Disadvantages}

- It is somewhat costly why because here we are using advanced processor and camera.

- And also it is less efficient because of the camera calibration.

\section{APPLICATIONS}

- The main and most important application is, used for blind people.

- And another application is detecting objects which are saved in its memory. 


\section{FUTURE WORK}

Here the efficiency of the robot is less when compared to the previously existing robot. So in feature we will try to increase the efficiency of the proposed system. And also in feature there may be a chance of implementing some more additional features because here we are using ARM11 processor which is an advanced one.

\section{REFERENCES}

[1]. B. Gates. (2007, Jan.). "A robot in every home," Sci. Amer. [Online] Available: http://www.sciam.com/article.cfm?id=a-robot-in-everyhome

[2]. T. W. Fong, I. Nourbakhsh, and K. Dautenhahn, "A survey of socially interactive robots," Robot. Auton. Syst., vol. 42, pp. 143-166, 2003

[3]. C. L. Nehaniv and K. Dautenhahn, Eds., Imitation and Social Learning in Robots, Humans, and Animals: Behavioural, Social and Communicative Dimensions. Cambridge, U.K.: Cambridge Univ. Press, 2004.

[4]. A. Billard, S. Calinon, R. Dillmann, and S. Schaal, "Survey: Robot programming by demonstration," Handbook of Robotics.NewYork: Springer, 2008, ch. 59.

[5]. A. L. Thomaz and C. Breazeal, "Teachable robots: Understanding human teaching behavior to build more effective robot learners," Artif. Intell. J., vol. 172, pp. 716737, 2008.

[6]. A. Thomaz and C. Breazeal, "Robot learning via socially guided exploration," in Proc. IEEE 6th Int. Conf. Dev. Learn., Jul. 2007, pp. 82-87.

[7]. S. Calinon, F. Guenter, and A. Billard, "On learning, representing, and generalizing a task in a humanoid robot," IEEE Trans. Syst.,Man, Cybern. B, Cybern., vol. 37, no. 2, pp. 286-298, Apr. 2007.

[8]. P. Miller, Theories of Developmental Psychology, 4th ed. New York: Worth, 2001.

[9]. S. Calinon and A. G. Billard. (2007). What is the teacher's role in robot programming by demonstration? toward benchmarks for improved learning, Interact. Stud. Spec. Issue Psychol. Benchmarks Human-Robot Interact. [Online]. vol. 8, no. 3, pp. 441-464. Available: http://citeseerx.

ist.psu.edu/viewdoc/summary?doi=10.1.1.73.2276

[10]. M. Tomasello, M. Carpenter, J. Call, T. Behne, and H. Moll, "Understanding and sharing intentions: The origins of cultural cognition," Behav. Brain Sci., vol. 28, no. 5, pp. 675-690, 2005 